\title{
Heart and Lung Transplantation
}

National Cancer Institute

\section{Source}

National Cancer Institute. Heart and Lung Transplantation. NCI Thesaurus. Code

C15247.

The surgical transfer of a heart and one or both lungs from one individual to another. 